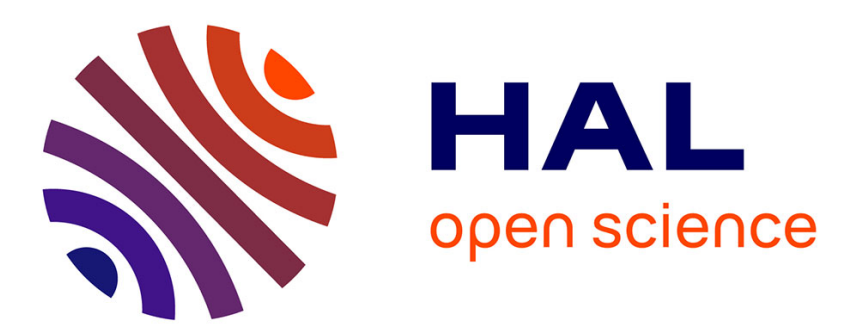

\title{
Removal of farm subsidies in a regional economy: a computable general equilibrium analysis
}

\author{
Francisco Javier de Miguel, Antonio Manresa
}

\section{To cite this version:}

Francisco Javier de Miguel, Antonio Manresa. Removal of farm subsidies in a regional economy: a computable general equilibrium analysis. Applied Economics, 2008, 40 (16), pp.2109-2120. 10.1080/00036840600949371 . hal-00582074

\section{HAL Id: hal-00582074 https://hal.science/hal-00582074}

Submitted on 1 Apr 2011

HAL is a multi-disciplinary open access archive for the deposit and dissemination of scientific research documents, whether they are published or not. The documents may come from teaching and research institutions in France or abroad, or from public or private research centers.
L'archive ouverte pluridisciplinaire HAL, est destinée au dépôt et à la diffusion de documents scientifiques de niveau recherche, publiés ou non, émanant des établissements d'enseignement et de recherche français ou étrangers, des laboratoires publics ou privés. 


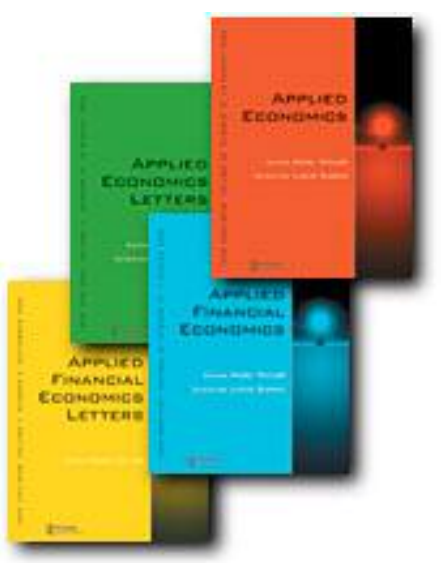

Removal of farm subsidies in a regional economy: a computable general equilibrium analysis

\begin{tabular}{|r|l|}
\hline Journal: & Applied Economics \\
\hline Manuscript ID: & APE-06-0096 \\
\hline Journal Selection: & Applied Economics \\
\hline JEL Code: & $\begin{array}{l}\text { C68 - Computable General Equilibrium Models < C6 - Mathematical } \\
\text { Methods and Programming < C - Mathematical and Quantitative } \\
\text { Methods, D58 - Computable and Other Applied General Equilibrium } \\
\text { Models }<\text { D5 - General Equilibrium and Disequilibrium < D - } \\
\text { Microeconomics, Q19 - Other < Q1 - Agriculture < Q - Agricultural } \\
\text { and Natural Resource Economics }\end{array}$ \\
\hline Keywords: & \begin{tabular}{l} 
farm subsidies, computable general equilibrium analysis \\
\hline
\end{tabular} \\
\hline
\end{tabular}




\title{
Removal of farm subsidies in a regional economy: a computable general equilibrium analysis
}

\author{
Francisco Javier de Miguel - University of Extremadura* \\ Antonio Manresa - University of Barcelona and CREB
}

\begin{abstract}
The purpose of this paper is to analyse the importance of farm subsidies for the Extremadura economy. To this end, a computable general equilibrium model for this region is presented, with which we analyse the economic effects caused by a simulated removal of these subsidies. Different scenarios involving the labour market rigidities and tax compensation are considered. Model parameters are determined by the procedure known as calibration, using a social accounting matrix constructed for this economy. The results clearly show the negative effects that this elimination would produce on the main micro and macroeconomic variables.
\end{abstract}

\footnotetext{
* Francisco Javier de Miguel. Department of Applied Economics. Faculty of Economics. University of Extremadura. Elvas Evenue. 06071. Badajoz. SPAIN. e-mail: demiguel@unex.es.
} 


\section{Introduction}

One of the features characterizing the economy of Extremadura - an Objective 1 Region of the European Union (EU) located in SW Spain - is the major weight that farming activities have in its production structure. Their relative share in terms of total value added (12.6\%) or employment $(24 \%)$ is far greater than is the case for the Spanish economy as a whole $(4.9 \% \text { and } 10.9 \% \text {, respectively })^{2}$.

Clearly related to this fact is the enormous significance of the farm subsidies received by the agriculture sector in Extremadura. For example, the proportions of the value added of this sector and of the regional GDP represented by these subsidies are close to $18 \%$ and $2.5 \%$, respectively. Apart from being large income injections for this sector, farm subsidies play an important role in fixing the population in rural areas and avoiding population movements towards urban zones $^{3}$.

The principal objective of the present work is to study the dependence of the Extremadura economy on these farm subsidies. A straightforward way of quantifying this dependence is to simulate the removal of these grants and to determine the effects of this scenario. Furthermore, since farm subsidies are financed by the EU, a simulation of this nature would allow one to approximate the current real scenario which is characterized by the enlargement of the EU to 25 member states, which could well involve a reduction in the subsidies received by the Extremadura agriculture.

As a second exercise, we consider the maintenance of these farm subsidies, but its payment is taken over by the Regional Government -not EU, financing it by a

\footnotetext{
${ }^{2}$ These percentages and the subsequent for subsidies are computed considering data for 1990. As it is noted below, statistical limitations are the reason for taking this year as reference for the analysis. More recent data again show a marked importance of the agriculture sector and farm subsidies in this region.

${ }^{3}$ These effects are, however, excluded from the subsequent analysis. For the incorporation of effects deriving from population shifts, see, for example, Kehoe and Noyola (1991).
} 
linear increase in the income tax rates. The aim of this second simulation is to illustrate an alternative possible economic policy that could mitigate the distortions caused by the removal of subsidies.

These two simulations produce changes that affect all economic sectors and agents in a significant way. It therefore seems necessary to use an analytical framework that includes all the inter-relationships and dependencies involved in the economy. In particular, we use a computable general equilibrium (CGE) model, with a level of disaggregation sufficient to allow the effects on individual agents and sectors to be captured, thereby going beyond the scope of aggregatetype macroeconomic models ${ }^{4}$.

The results of the first simulation clearly show the major negative effects that a hypothetical suppression of farm subsidies would have. For instance, a deterioration of economic activity is apparent in reduced sectoral activity levels, in increases in most of the prices considered, and in generalized welfare loses that are particularly marked for the higher income household groups.

The results of the second exercise, which include fiscal compensation via income tax, are different, especially in regard to the behaviour of prices. While there are greater welfare losses for the higher income households, the distortions in economic activity in this case are less than in the initial simulation.

The work is structured as follows. Section 2 describes in detail the model constructed for Extremadura. Section 3 gives a brief presentation of the social accounting matrix from which the model parameters are obtained. Section 4 analyzes the results of the two simulations. Finally, Section 5 presents the principal conclusions.

\footnotetext{
${ }^{4}$ Different regional CGE models have been applied to agricultural economic issues; see Partridge and Rickman (1998). On the other hand, various topics related to the Common Agricultural Policy have been analysed by means of CGE modelling; see, for example, Philippidis and Hubbard (2001), van Meijl and van Tongeren (2002), and Lips and Rieder (2005).
} 


\section{The model}

The computable general equilibrium model constructed for the Extremadura economy — henceforth, CGEM-EXT — consists of a set of equations that reflect the equilibrium conditions and behaviour of the different agents, which in general terms are considered to be producers, households, the public sector, and the foreign sector.

With respect to the level of disaggregation, the model distinguishes 10 production sectors, 9 commodities, and 11 household groups (Figure 1). With respect to the government, it incorporates a broad disaggregation of taxation and transfers. Finally, three foreign sectors are considered, corresponding to the rest of Spain (RS), European Community (EC), and rest of the world (RW).

\section{[FIGURE 1]}

\subsection{Producers}

The model assumes that each of the ten production sectors obtains a homogeneous product as output, employing a technology represented by a nested production function. At the first nesting level, the total production of each sector $\left(Q_{j}\right)$ is obtained as a Cobb-Douglas aggregate of the domestic output $\left(Q d_{j}\right)$ and the three external supplies, i.e., the imports from the three foreign sectors $\left(Q r s_{j}, Q e c_{j}\right.$ and $\left.Q r w_{j}\right)^{5}$. In the second nesting level, the domestic production is obtained with a fixed coefficients technology between intermediate inputs $\left(X_{i j}\right)$ and value added $\left(V A_{j}\right)$. Lastly, in the third level, the value added is obtained using a Cobb-Douglas technology to combine the primary factors capital $\left(K_{j}\right)$ and labour $\left(L_{j}\right)$. The

\footnotetext{
${ }^{5}$ This form of representing the total production is usually known as the Armington hypothesis. The underlying idea is that imports are imperfect substitutes for domestic products.
} 
expressions used for these three levels are the following:

$Q_{j}=\beta_{A j} Q d_{j}^{\delta d j} Q r s_{j}^{\delta r s j} Q e c_{j}^{\delta e c j} Q r w_{j}{ }^{\delta r w j}$

$Q d_{j}=\min \left\{X_{1 j} / a_{1 j}, X_{2 j} / a_{2 j}, \ldots, X_{10 j} / a_{10 j}, V A_{j} / v_{j}\right\}$

$V A_{j}=\beta_{j} K_{j}^{\alpha j} L_{j}^{1-\alpha j} \quad \forall j=1,2, \ldots, 10$

In these equations $\beta_{A j}$ and $\beta_{j}$ are scale parameters; $\delta d_{j}, \delta r s_{j}, \delta e c_{j}$ and $\delta r w_{j}$ are parameters that reflect the shares of domestic and imported production in the total production, normalized to sum to unity; the parameters $a_{z j}$ indicate the minimum amount of $z$ needed to obtain a unit of $j$; $v_{j}$ is a parameter reflecting the value added technical coefficient; and $\alpha_{j}$ and $\left(1-\alpha_{j}\right)$ are parameters representing the shares of the primary factors capital and labour with respect to the value added.

Finally, firms obtain their demands for inputs and supplies of outputs by maximising profits under these technological constraints.

\subsection{Households}

The utility function used for the different household groups is again a nested function, with two nesting levels in this case. In the first level, the utility is given as a CES function between an aggregate of consumption $\left(\mathrm{Cag}_{f}\right)$ and savings $\left(\mathrm{S}_{f}\right)$. In the second level, the consumption aggregate is a new CES function defined over the 9 categories of commodities. The expressions used are:

$$
\begin{aligned}
& U_{f}=\left[\beta c_{f} \operatorname{Cag}_{f}^{\phi f}+\left(1-\beta c_{f}\right) S_{f}^{\phi f}\right]^{1 / \phi f} \\
& \operatorname{Cag}_{f}=\left[\gamma_{1 f} C_{1 f}^{\rho f}+\gamma_{2 f} C_{2 f}^{\rho f}+\ldots+\gamma_{9 f} C_{9 f}^{\rho f}\right]^{1 / \rho f} \quad \forall f=1,2, \ldots, 11
\end{aligned}
$$

In these equations, $\beta c_{f}$ and $\gamma_{h f}$ represent the respective distribution parameters of the first and second CES functions; $\phi_{f}$ and $\rho_{f}$ are the substitution parameters; and $C_{h f}$ represents the consumption of commodity $h$ by household group $f$. 
The budget constraint on each household group can be expressed as:

$$
\sum_{h=1}^{9} p_{h}\left(1+t s_{h}\right)\left(1+v a t_{h}\right) C_{h f}+p_{i} S_{f} \leq Y D_{f} \quad \forall f=1,2, \ldots, 11
$$

The sum on the left-hand side reflects the expenditure in final consumption. In the CGEM-EXT, taxes on consumption were incorporated as duty on alcoholic beverages and tobacco — at a tax rate $t s_{h}$ for commodity $h$ - and value added tax -at an effective rate of $v a t_{h}$. The expression also includes private saving, which is valued in the model at the same price than savings/investment, $p_{i}$.

The right-hand side of inequality (6) represents disposable income, $Y D_{f}$. For most households, this income comes basically from selling their capital $\left(K_{f}\right)$ and labour $\left(L_{f}\right)$ endowments at the prices $r$ and $w$, respectively ${ }^{6}$. In addition, the households receive transfers from the public sector $\left(T P S_{f}\right)$, including unemployment benefits and pension payments ${ }^{7}$. They also receive net transfers from the foreign sectors $\left(T F S_{f}\right)$. Finally, the disposable income is given by deducting the employers's social contributions and income tax, whose rates are $\operatorname{esc}_{f}$ and $\tau_{f}$, respectively.

The resulting equation for the disposable income of household group $f$ is:

$Y D_{f}=\left(1-\tau_{f}\right)\left[r K_{f}+w L_{f}(1-u)+T P S_{f}+T F S_{f}-e s c_{f} w L_{f}(1-u)\right]$

As usual, each consumer derives the consumption demands by maximising his utility function subject to his budget constraint.

\subsection{Government}

On the one hand, the government produces public services, using the technology of the production sector $j_{10}$. On the other, it demands public services (public

\footnotetext{
${ }^{6}$ As will be described in detail below, the model includes the possibility that not all the labour factor is employed. In this sense, $u$ is an endogenous variable of the model that reflects the unemployment rate.

${ }^{7}$ Unemployment benefits are determined endogenously as a function of the changes in the
} 
consumption, $\left.C^{G}{ }_{j 10}\right)$ and investment $\left(C^{G}{ }_{i}\right)$. In this sense, we consider this agent to maximize the following Leontief utility function defined over public consumption and public investment:

$U^{G}=\min \left\{C^{G}{ }_{j 10}, \gamma^{G} \cdot C^{G}{ }_{i}\right\}$

where $\gamma^{G}$ is an economic policy parameter representing a fixed proportion between the two.

The budget constraint on the government can be expressed in the following form:

$p_{j 10} C_{j 10}^{G}+p_{i} C_{i}^{G} \leq R^{G}+p_{i} w_{i}^{G}-\sum_{f=1}^{11} T P S_{f}$

The left-hand side of this expression represents this agent's expenditure in public consumption and investment. The right-hand side includes the total tax revenue $\left(R^{G}\right)$, from which are deducted the transfers paid to the 11 household groups. $w_{i}^{G}$ represents public debt or bond issues made by the government to cover budget deficits, that can be purchased by other agents at the same price as savings/investment, $p_{i}$.

With respect to the tax revenue $R^{G}$, the model incorporates the employees' social contributions and the income tax as direct taxation. As indirect taxation, it includes taxes on alcoholic beverages and tobacco, value added tax, employers' social contributions, import duty, and net taxes on production - taxation minus subsidies. For the latter, the model takes farm subsidies to be financed, not by the Regional Government, but by the European Community foreign sector via income transfer. The simulations proposed in next section 4 are preciselyfocu sed on these farm subsidies.

unemployment rate. Pension payments are indexed to the consumption price index (cpi). 


\subsection{Foreign sector}

As was noted above, the model distinguishes three foreign sectors: rest of Spain (RS), European Community (EC), and rest of the world (RW). The treatment of these sectors is straightforward. Each one produces a different commerce good, using as inputs the exports from the Extremadura economy based on a fixed coefficients technology. As a consequence of this activity, and also considering transfers to the domestic agents, our economy can undergo into deficit with respect to the foreign sectors. These deficits must be materialized in savings of these foreign sectors in order to achieve macroeconomic equilibrium between savings and investment ${ }^{8}$.

\subsection{Labour market}

The model allows for the rigidities in the labour market, so that in equilibrium the unemployment rate may be positive ${ }^{9}$. In particular, we consider that workers offer the labour factor at a real wage rate that depends on the unemployment rate, but the adjustment is not enough to clear the labour market. This relationship between real wage and unemployment rate is expressed by the following equation:

$$
\left(\frac{w}{c p i}\right)=\left(\frac{1-u}{1-u_{0}}\right)^{\frac{1}{\beta_{d}}}
$$

where $(w / c p i)$ represents the real wage rate in the economy; $u$ is the unemployment rate; $u_{0}$ is a parameter representing the unemployment rate at the initial equilibrium; and $\beta_{d}$ is a parameter that represents the sensitivity of the real wage rate with respect to the unemployment rate.

\footnotetext{
${ }^{8}$ The model constructed for the Extremadura economy is static. In this sense, the treatment of investment and savings is relatively straightforward, since the model basically has to ensure that in equilibrium the aggregate savings are equal to the total investment of the economy.

${ }^{9}$ The capital factor, however, is always fully employed.
} 
This last parameter may take values between zero and infinity. If $\beta_{d}=0$, the real wage rate is adjusted sufficiently for the unemployment rate to remain constant and equal to the unemployment rate of the benchmark equilibrium. If $\beta_{d}=\infty$, the contrary is the case, i.e., the real wage rate remains constant, and it is the unemployment rate that is completely flexible. For intermediate values of $\beta_{d}$, as this parameter increases, so does wage rate rigidity, i.e., there is a decline in the sensitivity of the real wage rate with respect to the unemployment rate ${ }^{10}$.

The simulations to be presented below use two different values of this parameter $-\beta_{d}=0$ and $\beta_{d}=1.5^{11}$ - representing therefore two labour market scenarios.

\subsection{Equilibrium}

The concept of equilibrium used in the model is that of Walrasian competitive equilibrium, incorporating the government and the foreign sector together with producers and consumers -households. In particular, equilibrium in the economy is determined by a prices vector, an activity levels vector, and a set of aggregate variables that allow all the markets to be emptied except for the labour market, as was noted above. Also, all the agents in the model attain their corresponding optimal choices under the respective budget constraint, i.e., they verify their optimization problem.

With respect to the model closure, we apply a mixed closure rule. Firstly, we opt to keep the public sector activity level fixed. The aim with this is to show the adjustment of this sector and of the economy as a whole when there was no

\footnotetext{
${ }^{10}$ This aggregate specification for the labour market, similar to that used by Oswald (1982), may be interpreted as a tattonoment process. For further details, see Manresa and Sancho (2005). This specification has also been used in many of the CGE models developed for the Spanish economy. See, for example, Kehoe et al. (1989) and Polo and Sancho (1993).

${ }^{11}$ For the specification represented by Equation (10), this latter value of the parameter is sufficiently high, and yields results that do not differ greatly from those obtained for a value $\beta_{d}=$ $\infty$.
} 
modification of this activity level. This is found to be a suitable scenario for the fiscal simulations performed. For the foreign sector, we opt to keep the trade deficits fixed at the levels of the initial equilibrium, allowing the activity levels of these foreign sectors to vary.

\section{Model parameters and social accounting matrix for Extremadura}

Model parameters have been obtained by means of the usual calibration procedure, for which we required a social accounting matrix (SAM) for the Extremadura economy. In general terms, these matrices may be conceived of as an extension of the traditional input-output tables, since, together with transactions linked with the productive sphere, they also incorporate disaggregated information on expenditures and income of households, the government, and the foreign sector.

The calibration basically consists in assuming that the SAM represents an initial equilibrium of the economy, i.e., it involves determining the values of the parameters that satisfy this property. Furthermore, in this benchmark equilibrium, the units of measurement are taken to be such that all the prices and activity levels are unitary ${ }^{12}$.

In our case, it is possible to obtain practically the entirety of the model parameters by calibration ${ }^{13}$. It is only necessary to get external estimates of the elasticities of substitution in the CES consumption functions. To this end we use information relative to the Spanish economy as a whole (López-Salido, 1993).

The Extremadura matrix, used as the basis for the calibration, is for 1990, so that

\footnotetext{
${ }^{12}$ For further details, see Mansur and Whalley (1984).

${ }^{13}$ The values of the tax rates used in the model are also obtained by calibration, using the tax revenues data included in the social accounting matrix for Extremadura. These are therefore effective tax rates, and not nominal rates.
} 
this is the year taken as reference for the analysis ${ }^{14}$. Also, since the matrix is constructed specifically to calibrate the present model, there exists perfect concordance between the SAM and the model. Thus, together with the production sectors, commodities and household groups that were shown in Figure 1, the SAM-Extremadura-1990 also includes the aforementioned three foreign sectors, an aggregate capital account or savings/investment account, two accounts for the labour and capital factors, and the broad disaggregation of taxes considered in the model.

\section{Simulations and analysis of results}

Having constructed the model and determined the benchmark equilibrium, we perform various simulations focused on farm subsidies. In particular, we perform the two simulation exercises that will be described in the following.

Firstly, we establish an extreme scenario consisting of a hypothetical total removal of these subsidies, without modifying any other tax or transfer. The goal is to give a clear picture of the Extremadura economy's dependence on these subsidies, by quantifying the negative effects that their absence would have on the principal economic variables.

Although in practice such a wide-reaching modification does not seem likely, with this simulation we also want to highlight the uncertainty that exists with regard to the future of the subsidies received by the Extremadura agriculture. There contribute to this uncertainty, for example, the recent enlargement of the

\footnotetext{
${ }^{14}$ Indeed, this is the only social accounting matrix that has been constructed for the Extremadura economy. For further details, see De Miguel et al. (1998) and De Miguel (2003). An application of this SAM focused on inequality and income distribution can be found in De Miguel and Pérez (2006).

On the other hand, although it would be appropriate to update the matrix, there are especially severe statistical limitations in the present case which prevented us from constructing a reliable matrix referred to a more recent period. For instance, only a single 1990-year input-output table has been constructed for the Extremadura economy, and the currently existing statistics only show a very limited productive disaggregation.
} 
European Union, as well as the reforms of the Common Agricultural Policy.

Secondly, we perform a simulation including fiscal compensation via the income tax. In particular, in this second exercise the Regional Government is assumed to replace the foreign European Community sector as the agent financing farm subsidies, although, in order to maintain tax revenues constant, income tax rates are increased linearly. There are basically two reasons for using this tax to provide the fiscal compensation: its importance for the overall fiscal system in Spain, and because Spain's regional governments have a certain capacity to modify it.

The goal of this second simulation is to illustrate an alternative measure of economic policy that would buffer the negative effects observed in the first simulation. This exercise also showsthe $\mathrm{m}$ ajor consequences that the hypothetical regional government's maintenance of these subsidies would have for this economy, in a scenario characterized by a greater direct fiscal pressure on households ${ }^{15}$.

Before going on to the results, we must note that the great quantity of information yielded by the model needs to be presented synthetically. The results of the two simulations will therefore be discussed in terms of three major blocks of variables — prices, activity levels, and household welfare.

\subsection{Removal of farm subsidies}

With respect to the first simulation, Table 1 lists the percentage variations in the different prices for the two labour market scenarios $-\beta_{d}=0$ and $\beta_{d}=1.5$.

Beginning with production prices, one observes that, in general terms, the removal

\footnotetext{
15 Other simulations might include different fiscal compensation schemes. For example, together with the total removal of farm subsidies, one could consider a simultaneous increase in the taxation applied to the farming sector itself. A good candidate would be employer's social contributions, since these constitute an especially important fiscal load for the Spanish economy as a whole.
} 
of subsidies would cause these prices to rise. The agriculture sector $\left(j_{1}\right)$ clearly stands out, with increases of greater than $10 \%$ in both scenarios. Because of its link with this sector, there is also a major rise shown by the food, beverages, and tobacco industries sector $\left(j_{4}\right)$. There are also important increases experienced by chemicals and mining $\left(j_{3}\right)$ and other industries $\left(j_{5}\right)$, due on their dependence on the rest of Spain via imports and the major rises observed in the average price of imported products $p_{R S}$.

There are various sectors - basically services - that present small declines in production prices, due to the modification in factor prices caused by the elimination of subsidies. In this sense, in both scenarios there is a fall in the capital factor price $(r)$, which is sharper for the greater wage rate rigidity ${ }^{16}$. It is important to note that, in all the simulations, the wage rate $(w)$ remains constant due to it is used as numeraire of the $\operatorname{model}^{17}$.

Consumption prices also undergo a generalized rise. Again this is especially so for the commodities most closely linked to agriculture (food and non-alcoholic beverages, $h_{1}$; alcoholic beverages and tobacco, $h_{2}$ ). The consumption price index cpi presents percentage increments between $1 \%$ and $2.5 \%$, approximately.

[TABLE 1]

Table 2 lists the percentage changes in the different activity levels. For the production sectors, there is a generalized reduction, again especially in the agriculture $\left(j_{1}\right)$ and food, beverages, and tobacco industry $\left(j_{4}\right)$ sectors. This general

\footnotetext{
${ }^{16}$ This reduction in return on capital factor is determined by a decrease in capital demand respect to its supply -that remains fixed.

17 Therefore, all the price variations commented on in the paper actually represent relative variations, expressed in relation to this numeraire.
} 
reduction is closely linked to the decrease that takes place in consumption demand, which is particularly severe for the first two commodities, with reductions between $5 \%$ and $6.3 \%$ approximately ${ }^{18}$.

Returning to the production sectors, one observes two clear exceptions to the above behaviour - chemicals and mining $\left(j_{3}\right)$ and, above all, construction $\left(j_{6}\right)$. These are sectors whose production is to a great degree investment-oriented, and are given an impulse by the rise in investment activity that takes place in this case $^{19}$. Nevertheless, the general decline in sectoral activity levels causes a reduction in factor demand, leading to an increase of more than 1 percentage point in the unemployment rate with respect to the initial equilibrium ${ }^{20}$.

Finally, for most production sectors — except agriculture — the simulation also causes a fall in imports from the three foreign sectors. Given the closure rule employed, this leads to a reduction in their corresponding activity levels ${ }^{21}$.

\section{[TABLE 2]}

Table 3 gives the results for the changes caused by the removal of farm subsidies in the household groups' welfare. In order to obtain a monetary valuation of these changes, the equivalent variations $(E V)$ are calculated.

One observes that the equivalent variations are negative in sign in practically all

\footnotetext{
${ }^{18}$ The activity level of public services $\left(j_{10}\right)$ remains constant due to the model closure rule.

${ }^{19}$ Given the characteristics of the present model, the investment of the economy is determined by savings. In this simulation, there is a notable rise in aggregate savings. This is basically due to the increase in the European Community foreign sector savings from halting subsidies to farming activities.

${ }^{20}$ Given the labour market specification, changes in the unemployment rate only refer to the scenario which involves wage rate rigidity $-\beta_{d}=1.5$. As was noted above, in the case of absolute wage rate flexibility $-\beta_{d}=0$ - the unemployment rate remains constant.

${ }^{21}$ Particularly striking is the major reduction in the activity level for the rest of the world foreign sector. The reason is that the level of the Extremadura economy's exports to this foreign sector is very low in the initial equilibrium. So, to maintain the trade balance constant, a small alteration in
} 
cases. One can therefore state that the elimination of these subsidies would cause a generalized welfare $\operatorname{loss}^{22}$. The decline in the factor income received by households leads to a general reduction in disposable income. Given also that consumption prices and savings/investment price rise, the result is a clear fall in private savings and consumption, and hence a marked welfare reduction.

The greatest equivalent variations (in absolute value) correspond to the household groups $f_{7}, f_{6}, f_{5}$ and $f_{2}$, i.e., the high income groups experience the greatest welfare losses. These household groups present a notable share of capital factor incomes in their respective income structures, so they are the more affected by the reduction in return on this factor.

\section{[TABLE 3]}

\subsection{Farm subsidies and compensation with a linear increase in income tax}

The second simulation assumes that the Regional Government takes up the payment of farm subsidies that were initially financed by the European Community foreign sector. In order to cover them and maintain total tax revenue constant, the government simultaneously imposes a linear increase in income tax rates.

The results in this case present major differences from those of the initial simulation. This is clearest in the behaviour of relative prices (Table 4). There is a fall in all the production and consumption prices, in the price of savings/investment, and in the three average prices of imported products.

imports from this foreign sector is translated into relatively large variations in its activity level.

22 There is a single household group whose welfare improves, albeit very slightly. This is the group $f_{3}$ in the scenario corresponding to $\beta_{d}=1.5$. In this scenario, this group has a small reduction in factor income, but its unemployment benefits are clearly greater than those of the initial equilibrium. 
Particularly noteworthy is the different behaviour of the production and consumption prices most closely linked to agriculture. Taking the agriculture sector itself as reference, in contrast with the first simulation, which gave increases of approximately $10 \%$, in this case there are declines of between $0.35 \%$ and $0.85 \%{ }^{23}$.

Furthermore, for each labour market scenario, there is little difference in the changes in production prices and consumption prices between the different sectors. The explanation is that the change imposed does not initially affect production structures, but instead is basically a change in demand.

\section{[TABLE 4]}

Table 5 presents the results for the changes in activity levels. There is a decline in the production sector levels, although generally far less pronounced than in the first simulation. Again, chemicals and mining $\left(j_{3}\right)$ and construction $\left(j_{6}\right)$ are exceptions to the general pattern. There is also a fall in the activity levels $Y_{h}$, reflecting a reduction in consumption demand - these falls are fairly similar for the different commodities, and are in general also less than in the first simulation. Finally, there are slight declines in the activity levels of the three foreign sectors, reflecting a minor reduction in imported products.

[TABLA 5]

\footnotetext{
${ }^{23}$ It is important to bear in mind that, unlike the first simulation, in this second exercise farming activities do receive the corresponding subsidies.
} 
The welfare effects for the different household groups are presented in Table 6 . One observes that in all cases there again occur welfare losses. The equivalent variations clearly show the group $f_{7}$ to be the worst affected, that is to say, the non-farming group with the highest incomes, and that supports the highest income tax rate. This result is similar to that obtained in the previous simulation, although it is now far more accentuated.

\section{[TABLE 6]}

To conclude the analysis, we present a brief comparison between the two previous simulations. This comparison shows whether, in the case that the European Community foreign sector stops subsidizing farming activities, the maintenance of these subsidies by the Regional Government financing them by a surcharge on income tax would be an appropriate measure of economic policy ${ }^{24}$. In general terms, the results seem to indicate that, if the Extremadura households are willing to support this greater direct fiscal load, the maintenance of these farm subsidies would indeed generate smaller distortions on this economy than their removal.

By way of example, it was already noted above that the reductions in activity levels in this second simulation are clearly less than those in the first exercise. Indeed, in contrast to the rise in unemployment rate in the first simulation, in the second exercise this rate falls by 0.4 percentage points. No such clear conclusion could be drawn, however, with respect to the welfare of the different household groups. Although, compared to the initial simulation, there are smaller welfare losses in the second simulation for most groups, there are various exceptions to this general pattern (see the household groups $f_{7}$ to $f_{11}$ ).

\footnotetext{
${ }^{24}$ The variable representing this linear increase in income tax rates is close to $30 \%$ in both labour
} 


\section{Conclusions}

The enormous importance of farm subsidies for the Extremadura economy leads us to study the dependence and the economic impact of different scenarios involving the elimination of these subsidies.

The modelling framework chosen for the simulations includes a full incorporation of the interdependences between the different economic agents. In particular, we use a static computable general equilibrium model, which captures the changes in the allocation of resources and the importance of the effects that are produced. It is important to emphasize the utility of this analytical framework for economic policy simulations, since it allows one to observe the micro and macroeconomic effects that result from different policy decisions.

The first exercise that is carried out brings out this relationship of dependence very clearly. This simulation corresponds to an extreme scenario consisting of the total removal of the subsidies. The resulting negative effects on the Extremadura economy are primarily evident in a notable reduction in the welfare levels of practically all the household groups, especially in the groups whose income depends to a major degree on the capital factor. There is also a generalized reduction in the different activity levels, and rises in most of prices -relative to wages- considered, with the sharpest changes for the sectors and commodities more linked to agriculture.

On the basis of this first exercise, the second simulation corresponds to a possible alternative fiscal policy aimed at mitigating the above negative effects. In particular, this second simulation considers that the farm subsidies are maintained by the Regional Government, which finances them by an increased fiscal pressure through income tax rates. Although in this simulation the welfare losses for the

market scenarios. 
higher income tax rate households are reinforced, the distortions caused to Extremadura economic activity in general seem to be less than in the initial simulation.

\section{REFERENCES:}

De Miguel, F.J. (2003) Matrices de contabilidad social y modelización de equilibrio general: una aplicación para la economía extremeña, Unpublished PhD Thesis, Universidad de Extremadura.

De Miguel, F.J. and Pérez, J. (2006) Linear SAM models for inequality changes analysis: an application to the Extremadurian economy, Applied Economics, forthcoming.

De Miguel, F.J.; Manresa, A. and Ramajo, J. (1998) Matriz de contabilidad social y multiplicadores contables: una aplicación para Extremadura, Estadística Española, 40, 195-232.

Ginsburgh, V. and Keyzer, M. (1997) The structure of applied general equilibrium models, MIT Press.

Kehoe, T.; Manresa, A.; Polo, C. and Sancho, F. (1989) Un análisis de equilibrio general de la reforma fiscal de 1986 en España, Investigaciones Económicas, XIII (3), 337-385.

Kehoe, T. and Noyola, P. (1991) Un modelo de equilibrio general para el análisis de la emigración urbana en México, Cuadernos Económicos del ICE, 48, 215237.

Lips, M. and Rieder, P. (2005) Abolition of raw milk quota in the European Union: a CGE analysis at the member country level, Journal of Agricultural Economics, 56 (1), 1-16. 
López-Salido, J.D. (1993) Consumo y ciclo vital: resultados para España con datos de panel, Investigaciones Económicas, XVII (2), 285-312.

Manresa, A. and Sancho, F. (2005) Implementing a double dividend: recycling ecotaxes towards lower labour taxes, Energy Policy, 33, 1577-1585.

Mansur, A. and Whalley, J. (1984) Numerical specification of applied general equilibrium models: estimation, calibration and data, in Applied general equilibrium analysis, H. Scarf and J. Shoven, Cambridge University Press.

Oswald, A. (1982) The microeconomic theory of the trade union, The Economic Journal, 22, 576-595.

Partridge, M and Rickman, D. (1998) Regional computable general equilibrium modelling. A survey and critical appraisal, International Regional Science Review, 21 (3), 205-248.

Philippidis, G. and Hubbard, L.J. (2001) The economic cost of the CAP revisited, Agricultural Economics, 25 (2), 375-385.

Polo, C. and Sancho, F. (1993) An analysis of Spain's integration in the EEC, Journal of Policy Modelling, 15 (2), 157-178.

Shoven, J. and Whalley, J. (1984) Applied general-equilibrium models of taxation and international trade: an introduction and survey, Journal of Economic Literature, XXII, 1007-1051.

Shoven, J. and Whalley, J. (1992) Applying general equilibrium, Cambridge University Press.

van Meijl, H. and van Tongeren, F. (2002) The Agenda 2000 CAP reform, world prices and GATT-WTO export constraints, European Review of Agricultural Economics, 29 (4), 445-470. 


\section{ACKNOWLEDGEMENTS}

This work has been supported by the Ministerio de Ciencia y Tecnología (SEC2003-06080) and by the Generalitat de Catalunya (2004XT00095). The second author also acknowledges a Ministerio de Ciencia y Tecnología grant (SEC2003-06630) and financial support from the Generalitat de Catalunya (2001SGR00029). 
Figure 1. Production sectors, commodities and household groups

\section{included in the CGEM-EXT model}

\section{PRODUCTION SECTORS:}

$i_{1}$ - Agriculture

$j_{2}$ - Energy

$j_{3}-$ Chemicals and mining

$j_{4}-$ Food, beverages and tobacco

$j_{5}-$ Other industries

\section{COMMODITIES:}

$h_{1}-$ Food and non-alcoholic beverages

$h_{2}-$ Alcoholic beverages and tobacco

$h_{3}-$ Clothing and footwear

$h_{4}-$ Housing, heating and lighting

$h_{5}-$ Furnishing and fittings

\section{HOUSEHOLD GROUPS:}

$f_{1}-$ Younger than 65 , farming sector, low income $f_{2}$ - Younger than 65 , farming sector, high income

$f_{3}$ - Younger than 65 , other sectors, 1 st income quintile

$f_{4}$ - Younger than 65 , other sectors, 2nd income quintile

$f_{5}$ - Younger than 65 , other sectors, 3rd income quintile

$f_{6}$ - Younger than 65 , other sectors, 4 th income quintile

\author{
$j_{6}-$ Construction \\ $j_{7}-$ Trade \\ $j_{8}-$ Transports and communications \\ $j_{9}-$ Other private services \\ $j_{10}-$ Public services
}

\author{
$h_{6}-$ Medical services \\ $h_{7}$ - Transports and communications \\ $h_{8}$ - Leisure, education and culture \\ $h_{9}-$ Other commodities
}

$f_{7}$ - Younger than 65 , other sectors, 5 th income quintile

$f_{8}-65$ or older, rural setting, low income

$f_{9}-65$ or older, rural setting, high income

$f_{10}-65$ or older, urban setting, low income

$f_{11}-65$ or older, urban setting, high income 
Table 1. First simulation: Removal of farm subsidies.

\section{Percentage variation in PRICES}

\begin{tabular}{|c|c|c|c|}
\hline \multicolumn{2}{|c|}{ Production } & \multirow{2}{*}{$\begin{array}{c}\boldsymbol{\beta}_{\boldsymbol{d}}=\boldsymbol{0} \\
12.59\end{array}$} & \multirow{2}{*}{$\begin{array}{c}\boldsymbol{\beta}_{\boldsymbol{d}}=1.5 \\
10.83\end{array}$} \\
\hline$j_{1}$ & Agriculture & & \\
\hline$j_{2}$ & Energy & 0.91 & -0.8 \\
\hline$j_{3}$ & Chemicals and mining & 4.77 & 3.18 \\
\hline$j_{4}$ & Food, beverages, and tobacco & 6.16 & 4.57 \\
\hline$j_{5}$ & Other industries & 4.93 & 3.41 \\
\hline$j_{6}$ & Construction & 0.91 & -0.22 \\
\hline$j_{7}$ & Trade & 0.73 & -0.58 \\
\hline$j_{8}$ & Transports and communications & 0.64 & -0.5 \\
\hline$j_{9}$ & Other private services & -0.88 & -2.39 \\
\hline$j_{10}$ & Public services & 0.43 & 0.06 \\
\hline \multicolumn{4}{|c|}{ Consumption (commodities) } \\
\hline$h_{1}$ & Food and non-alcoholic beverages & 5.59 & 4.05 \\
\hline$h_{2}$ & Alcoholic beverages and tobacco & 4.36 & 2.86 \\
\hline$h_{3}$ & Clothing and footwear & 2.6 & 1.2 \\
\hline$h_{4}$ & Housing, heating, and lighting & 0.14 & -1.32 \\
\hline$h_{5}$ & Furnishings and fittings & 1.96 & 0.72 \\
\hline$h_{6}$ & Medical services & 2.67 & 1.25 \\
\hline$h_{7}$ & Transports and communications & 1.9 & 0.49 \\
\hline$h_{8}$ & Leisure, education, and culture & 1.28 & -0.14 \\
\hline$h_{9}$ & Other commodities & 1.23 & -0.22 \\
\hline cpi & Consumption price index & 2.47 & 1.02 \\
\hline \multicolumn{4}{|c|}{ Investment } \\
\hline$i$ & Investment & 1.62 & 0.45 \\
\hline \multicolumn{4}{|c|}{ Weighted average price of imported products } \\
\hline$R S$ & Rest of Spain & 6.12 & 4.45 \\
\hline$E C$ & European Community & 7.05 & 5.46 \\
\hline$R \boldsymbol{W}$ & Rest of the world & 7.48 & 5.88 \\
\hline \multicolumn{4}{|c|}{ Primary factors } \\
\hline$r$ & Capital & -2.11 & -4.14 \\
\hline$w$ & Labour & Numeraire & Numeraire \\
\hline
\end{tabular}

Source: The authors' own elaboration. 
Table 2. First simulation: Removal of farm subsidies.

Percentage variation in ACTIVITY LEVELS

\begin{tabular}{|c|c|c|c|}
\hline \multicolumn{2}{|c|}{ Production } & $\beta_{d}=0$ & $\beta_{d}=1.5$ \\
\hline$j_{1}$ & Agriculture & -3.51 & -4.13 \\
\hline$j_{2}$ & Energy & -2.46 & -3.08 \\
\hline$j_{3}$ & Chemicals and mining & 2.73 & 1.08 \\
\hline$j_{4}$ & Food, beverages, and tobacco & -4.41 & -4.63 \\
\hline$j_{5}$ & Other industries & -0.38 & -1.1 \\
\hline$j_{6}$ & Construction & 6.56 & 6.04 \\
\hline$j_{7}$ & Trade & -2.54 & -2.6 \\
\hline$j_{8}$ & Transports and communications & -0.04 & -0.84 \\
\hline$j_{9}$ & Other private services & -0.72 & -0.97 \\
\hline$j_{10}$ & Public services & - & - \\
\hline \multicolumn{4}{|c|}{ Commodities } \\
\hline$h_{1}$ & Food and non-alcoholic beverages & -6.3 & -5.91 \\
\hline$h_{2}$ & Alcoholic beverages and tobacco & -5.33 & -4.96 \\
\hline$h_{3}$ & Clothing and footwear & -3.74 & -3.44 \\
\hline$h_{4}$ & Housing, heating, and lighting & -1.22 & -0.83 \\
\hline$h_{5}$ & Furnishings and fittings & -3.15 & -3.05 \\
\hline$h_{6}$ & Medical services & -3.86 & -3.56 \\
\hline$h_{7}$ & Transport and communications & -3.23 & -2.95 \\
\hline$h_{8}$ & Leisure, education, and culture & -2.63 & -2.33 \\
\hline$h_{9}$ & Other commodities & -2.59 & -2.27 \\
\hline \multicolumn{4}{|c|}{ Foreign sectors } \\
\hline$R S$ & Rest of Spain & -3.57 & -4.41 \\
\hline$E C$ & European Community & -1.97 & -2.68 \\
\hline $\boldsymbol{R} \boldsymbol{W}$ & Rest of the world & -19.77 & -21.52 \\
\hline
\end{tabular}

Source: The authors' own elaboration.

Table 3. First simulation: Suppression of farm subsidies.

EQUIVALENT VARIATIONS (thousands of millions pesetas)

\begin{tabular}{|c|c|c|}
\hline & $\beta_{d}=0$ & $\beta_{d}=1.5$ \\
\hline$f_{1}$ - Younger than 65, farming sector, low income & -1.19 & -0.9 \\
\hline$f_{2}$ - Younger than 65 , farming sector, high income & -2.58 & -2.76 \\
\hline$f_{3}$ - Younger than 65, other sectors, 1 st quintile & -0.75 & 0.09 \\
\hline$f_{4}$ - Younger than 65 , other sectors, 2 nd quintile & -1.6 & -1.32 \\
\hline$f_{5}$ - Younger than 65 , other sectors, 3rd quintile & -3.12 & -3.06 \\
\hline$f_{6}$ - Younger than 65 , other sectors, 4th quintile & -4.28 & -4.29 \\
\hline$f_{7}$ - Younger than 65 , other sectors, 5th quintile & -9.29 & -10.36 \\
\hline$f_{8}$ - 65 years or more, rural, low income & -0.22 & -0.22 \\
\hline$f_{9}-65$ years or more, rural, high income & -1.88 & -2.02 \\
\hline$f_{1 o}-65$ years or more, urban, low income & -0.01 & -0.02 \\
\hline$f_{11}$ - 65 years or more, urban, high income & -0.71 & -0.83 \\
\hline
\end{tabular}

(a)

Source: The authors' own elaboration. 
Table 4. Second simulation: Farm subsidies and linear change in income tax.

\section{Percentage variation in PRICES}

\begin{tabular}{|c|c|c|c|}
\hline \multicolumn{2}{|c|}{ Production } & \multirow{2}{*}{$\begin{array}{c}\boldsymbol{\beta}_{\boldsymbol{d}}=\boldsymbol{0} \\
-0.84\end{array}$} & \multirow{2}{*}{$\begin{array}{c}\beta_{d}=1.5 \\
-0.34\end{array}$} \\
\hline$j_{1}$ & Agriculture & & \\
\hline$j_{2}$ & Energy & -0.91 & -0.36 \\
\hline$j_{3}$ & Chemicals and mining & -0.82 & -0.33 \\
\hline$j_{4}$ & Food, beverages, and tobacco & -0.8 & -0.32 \\
\hline$j_{5}$ & Other industries & -0.78 & -0.31 \\
\hline$j_{6}$ & Construction & -0.6 & -0.24 \\
\hline$j_{7}$ & Trade & -0.7 & -0.28 \\
\hline$j_{8}$ & Transports and communications & -0.61 & -0.24 \\
\hline$j_{9}$ & Other private services & -0.82 & -0.33 \\
\hline$j_{10}$ & Public services & -0.19 & -0.08 \\
\hline \multicolumn{4}{|c|}{ Consumption (commodities) } \\
\hline$h_{l}$ & Food and non-alcoholic beverages & -0.78 & -0.31 \\
\hline$h_{2}$ & Alcoholic beverages and tobacco & -0.77 & -0.31 \\
\hline$h_{3}$ & Clothing and footwear & -0.74 & -0.29 \\
\hline$h_{4}$ & Housing, heating, and lighting & -0.79 & -0.31 \\
\hline$h_{5}$ & Furnishings and fittings & -0.65 & -0.26 \\
\hline$h_{6}$ & Medical services & -0.74 & -0.3 \\
\hline$h_{7}$ & Transports and communications & -0.74 & -0.3 \\
\hline$h_{8}$ & Leisure, education, and culture & -0.76 & -0.3 \\
\hline$h_{9}$ & Other commodities & -0.77 & -0.31 \\
\hline cpi & Consumption price index & -0.76 & -0.3 \\
\hline \multicolumn{4}{|c|}{ Investment } \\
\hline$i$ & Investment & -0.61 & -0.24 \\
\hline \multicolumn{4}{|c|}{ Weighted average price of imported products } \\
\hline$R S$ & Rest of Spain & -0.85 & -0.34 \\
\hline$E C$ & European Community & -0.8 & -0.32 \\
\hline $\boldsymbol{R} \boldsymbol{W}$ & Rest of the world & -0.8 & -0.32 \\
\hline \multicolumn{4}{|c|}{ Primary factors } \\
\hline$r$ & Capital & -1.12 & -0.45 \\
\hline$w$ & Labour & Numeraire & Numeraire \\
\hline
\end{tabular}

Source: The authors' own elaboration. 
Table 5. Second simulation: Farm subsidies and linear change in income tax. Percentage variation in ACTIVITY LEVELS

\begin{tabular}{|c|c|c|c|}
\hline \multicolumn{2}{|c|}{ Production } & $\beta_{d}=0$ & $\beta_{d}=1.5$ \\
\hline$j_{1}$ & Agriculture & -0.61 & -0.4 \\
\hline$j_{2}$ & Energy & -0.59 & -0.38 \\
\hline$j_{3}$ & Chemicals and mining & 1.84 & 2.24 \\
\hline$j_{4}$ & Food, beverages, and tobacco & -1.25 & -1.12 \\
\hline$j_{5}$ & Other industries & -0.15 & 0.07 \\
\hline$j_{6}$ & Construction & 6.16 & 6.9 \\
\hline$j_{7}$ & Trade & -1.6 & -1.51 \\
\hline$j_{8}$ & Transports and communications & 0.08 & 0.32 \\
\hline$j_{9}$ & Other private services & -1.16 & -1.03 \\
\hline$j_{1 o}$ & Public services & - & - \\
\hline \multicolumn{4}{|c|}{ Commodities } \\
\hline$h_{1}$ & Food and non-alcoholic beverages & -2.25 & -2.25 \\
\hline$h_{2}$ & Alcoholic beverages and tobacco & -2.23 & -2.23 \\
\hline$h_{3}$ & Clothing and footwear & -2.4 & -2.37 \\
\hline$h_{4}$ & Housing, heating, and lighting & -2.42 & -2.42 \\
\hline$h_{5}$ & Furnishings and fittings & -2.71 & -2.61 \\
\hline$h_{6}$ & Medical services & -2.29 & -2.26 \\
\hline$h_{7}$ & Transports and communications & -2.38 & -2.34 \\
\hline$h_{8}$ & Leisure, education, and culture & -2.57 & -2.54 \\
\hline \multicolumn{2}{|c|}{\begin{tabular}{l|l}
$h_{9}$ & Other commodities \\
\end{tabular}} & -2.55 & -2.51 \\
\hline \multicolumn{4}{|c|}{\begin{tabular}{|l|} 
Foreign sectors \\
\end{tabular}} \\
\hline$R S$ & Rest of Spain & -0.29 & -0.03 \\
\hline$E C$ & European Community & -0.01 & -0.2 \\
\hline $\boldsymbol{R} \boldsymbol{W}$ & Rest of the world & -3.29 & -2.59 \\
\hline
\end{tabular}

Source: The authors' own elaboration.

Table 6. Second simulation: Farm subsidies and linear change in income tax. EQUIVALENT VARIATIONS (thousands of millions pesetas)

\begin{tabular}{|l|c|c|}
\hline & $\boldsymbol{\beta}_{\boldsymbol{d}}=\boldsymbol{0}$ & $\boldsymbol{\beta}_{\boldsymbol{d}}=\mathbf{1 . 5}$ \\
\hline $\boldsymbol{f}_{\boldsymbol{1}}$ - Younger than 65, farming sector, low income & -0.46 & -0.53 \\
\hline $\boldsymbol{f}_{2}$ - Younger than 65, farming sector, high income & -1.52 & -1.38 \\
\hline $\boldsymbol{f}_{3}$ - Younger than 65, other sectors, 1st quintile & -0.36 & -0.6 \\
\hline $\boldsymbol{f}_{4}$ - Younger than 65, other sectors, 2nd quintile & -0.52 & -0.58 \\
\hline $\boldsymbol{f}_{5}$ - Younger than 65, other sectors, 3rd quintile & -1.69 & -1.62 \\
\hline $\boldsymbol{f}_{\boldsymbol{6}}$ - Younger than 65, other sectors, 4th quintile & -2.63 & -2.49 \\
\hline $\boldsymbol{f}_{7}$ - Younger than 65, other sectors, 5th quintile & -12.37 & -11.44 \\
\hline $\boldsymbol{f}_{\boldsymbol{g}}$ - 65 years or more, rural, low income & -0.49 & -0.46 \\
\hline $\boldsymbol{f}_{\boldsymbol{g}}-\mathbf{6 5}$ years or more, rural, high income & -2.13 & -1.98 \\
\hline $\boldsymbol{f}_{10}-\mathbf{6 5}$ years or more, urban, low income & -0.17 & -0.16 \\
\hline $\boldsymbol{f}_{11}-\mathbf{6 5}$ years or more, urban, high income & -1.61 & -1.49 \\
\hline
\end{tabular}

Source: The authors' own elaboration. 